\title{
The Aesthetics of Nature Tourism Through the Philosophical Perspective of Immanuel Kant
}

\author{
Myrza Rahmanita ${ }^{1 *}$ \\ ${ }^{1}$ Sekolah Tinggi Pariwisata Trisakti, Jakarta, Indonesia \\ myrzarahmanita@stptrisakti.ac.id
}

\begin{abstract}
This study is an attempt to explore aesthetics conception of nature tourism using the philosophical perspective of Immanuel Kant. Aesthetics is a branch of philosophy tree that discusses the essence of beauty, while nature tourism is a travel activity undertaken by a person or group to various landscapes for the purposes of leisure, business and pleasure; where nature is admired for its tranquility, relaxing, beauty and aesthetics potentials. This is in line with Kant's conception of 'pleasure in beauty'. This exploration is conducted using descriptive by means of literature review method upon a number ofworks, especially Kant's philosophical thoughts on tourism aesthetics. The results of this investigation indicates that, firstly, an arrangement of pleasure in tourism is found in beauty of nature; secondly, beauty of nature is a subjective appreciation but not merely personal (universal); thirdly, natural beauty consists of perfect beauty and sublime. In the case of sublime, tourists must fight their imagination so they are able to turn their fear and threats of nature into pleasure; and finally, the aesthetics of tourism is a symbol of morality though beauty of nature. The recommendation of this study is to conduct further study on the aesthetics of nature tourism especially in relation to morality.
\end{abstract}

Keywords-Tourism, Aesthetic, Kant, Beauty, Sublime.

\section{I.INTRODUCTION}

Tourism, including nature tourism is almost always associated with beauty. Beauty itself belongs to the realm of aesthetics. Aesthetics is a branch of philosophy, particularly the philosophy of values (axiology) that discusses the nature of beauty. Axiology, along with ontology and epistemology of tourism are the constructing elements of tourism as an independent social science. The study of tourism and beauty often known as the aesthetics of tourism. Obasi described tourism aesthetics as a study of aesthetic activity and aesthetic value by means of traveling (Obasi, N. T., 2015). Tribe in his book of 'Introduction to Philosophical Issues in Tourism' links tourism with three philosophical queries that is truth, beauty and virtue (Tribe, J. Ed., 2009). Nature tourism aesthetics is then a reflection to the question of what is this thing called 'beauty' especially in the field of nature tourism. With regard to Kant, Hammimaster says that from Kant's point of view, most of his aesthetics judgments are not about art, but nature; they are about beauty in natural objects and people experiencesabout sublime (Hammimaster, Kai., 2002).

The aesthetics of nature tourism is a conception about the meaning of beauty in nature tourism. It is a matter of attaining knowledge about beauty as to whetherbeauty of nature lies in the realm of nature itself, apart from the personal mind of people who enjoy it as described by 'empirist' or is it lies in the minds of people who enjoy beauty as pronounced by 'rationalist'? What is the connection between beauty and pleasure? So that the aesthetics of nature tourism has a substantial position in both the science of tourism as well as in the practice of tourism, especially associated to nature tourism.

Nature tourism can clearly be distinguished from cultural tourism and creative tourism. It is reflected that the existence of aesthetics construction of nature tourism is an enrichment to the aesthetics construction of tourism. Therefore, this study was piloted as an effort to build aesthetics construction of nature tourism, directed at somewhat philosophical level through the adoption of several works discussing the aesthetics construction of nature tourism, in particular through thephilosophical perspective of Immanuel Kant, a Konigsberg-born philosopher. It is Kant's aesthetics thought that emphasizes pleasure in terms of beauty which in his 'Critique of Judment' termed as pleasure in beauty (Kant, I., 2000). Pleasure in tourism is considered a tourism motivation that people are traveling to attain pleasure. This work is then conducted as an attempt to answer the research 
question of what is the construction of aesthetics thinking of nature tourism through philosophical perspective of Immanuel Kant?

\section{II.Literature Review}

Tourism is a movement or activities of people traveling away from their usual environment for a short period of time, not longer that one consecutive year; to engage in leisure, business, pleasureor other purposes other than to live, study and work; including taking part in any activities from origin destination to, during in, and from targeted destinations; which may occur through interaction concerningtourists, businesses, governments and local communities; beyond which studies on tourism can and should be conducted (Rahmanita,Myrza, 2004).

Most scholars define nature tourism as leisure activities taking place in nature areas, with its substantial componentsarevisitor (imparting a factor of being away from home) and experiences; both play the key roles (Fredman, P. \& Tyrväinen, L., 2006). Tourists' quest is for beauty (Barretto, M., 2011). Nature tourism that sometimes known as nature-based tourism or nature-oriented tourism is a style of tourism which is based on the enjoyment of natural areas and the observation of nature [8]that combines education, recreation and often adventure (Laarman, J.G., Perdue, R.R., 1988) with its dimensions of experience, style and location (Valentine, Peter S., 1992).

Nature tourism cannot be separated from 'beauty' which can be found everywhere. As Emerson says, nature can reveal its beauty in all places and at all times to the eye of those who know how to look for it. He also says about emotional or affective component in 'beauty of intellect' just as there is in the immediate 'beauty of perception'. Further he mentions about close parallel of goodness and beauty in nature. Emerson concludes that nature is the source of truth, goodness, and beauty and this view of nature includes an inherent call to protect of what is true, good, and beautiful. These are the things that human beings are searching for, and striving after. Emerson's idea later relate to morality.

Beauty.The concept of beauty is different than'aesthetic'. Discussionsabout 'beauty' has been started since the period of Ancient Greek by Great Philosophers like Socrates, Plato,etcetera; way before the expressionof 'aesthetic' was coined (Mirbach, D., 2009). Beauty is used in three different concepts that is,beauty in the broadest sense; beauty in a purely aesthetic sense; beauty in the aesthetic sense (Tatarkiewicz, Wladysla, 1992) The original Greek concept of beautyincludes beauty of morals, ethics and aesthetics. Similar ideas can be found in the contention of "medieval dictum,pulchrum et perfectum idem est" (beautiful and perfect are the same). Some greatest thinkers of different periods have made their opinions related to beauty, such asthat "which being good is also pleasant" (Aristotle) or that "which pleases when it is perceived" (Thomas Aquinas). The Sophists in Athens have narrowed the initial conception and definesbeauty asthat "which is pleasant to sight or hearing". Mendelssohn states that beauty as a sensual phenomenon is part of the realm of change about which ultimate truth statements cannot be made due to its ephemeral character (Hammimaster, Kai., 2002). According to Kant, beauty is the form of the purposiveness of an object, insofar as it isperceived in it without representation of an end (Kant, I. , 2000).

Aesthetics. The term aesthetics originates from a Greek word aisthesis $(\alpha 1 \sigma \delta \varepsilon \sigma 1 \sigma)$ which means 'perception', 'sensation', refering to the philosophical theory of sensation perception in relation to beauty, art and perception about it (Obasi, N. T., 2015). Dichotomy and antithesis between 'esthetic' (perception, sensation) and 'noesthetic'(reason, knowledge) inwestern evolution of thinking often opposes the two. As 'perception' and 'sensation' in one hand being confronted with 'reason' and 'knowledge' in another, it becomes the upbringing for aesthetics to grow into a philosophical discipline.

Aesthetics by Baumgarten. Alexander Gottlieb Baumgarten (1714-1762) in "Aesthetica" coined the term aesthetics as a philosophical discipline, branched out from the common western way of thinking at that time. Baumgarten uses the term aesthetics to differentiate intellectual knowledge to sensation knowledge, that in his opinion, aesthetics is more sensation knowledge (scientia cognitionis sensitivae) rather than intellectual knowledge.He defines aesthetics as theoria liberalium atrium that is liberal art theory; gnoseologia inferior or lower level of knowledge theory; ars pulcre cogitandi, the art of beauty way of thinking; and ars analogy rationis, the art of rational analogy. Baumgarten states that previous philosophers describe aesthetics as "theory of beauty" or "philosophy of sensitivity" (Obasi, N. T., 2015). 
Previous Studies on Tourism Aesthetics. Previous studies have been conducted on the topic of tourism aesthetics. One of them belongs to Barretto. His study (Barretto, M., 2013) of the "Aesthetics and Tourism"discusses a number of opinions, linking tourism with human desire for beauty that has existed since the beginning of human life. Barretto sees the aesthetics role in tourism experiences but has not yet comes to constructing the substance of tourism aesthetics thoughts.

Zhang and Ma (Peiyin Zhang and Chao Ma, 2011) held a studythat can be found in their book, the "Research on Value and Approaches of Tourism Aesthetic Construction'. They said that aesthetics culture of tourism is attached to the level of culture, refering to product design by applying artistic and aesthetic principles. According to Zhang and Ma, basic aesthetics construction of tourism is a mixture of aesthetics abilities of living creatures; aesthetics attributes of traveling; and cultural tastes of traditional tourism. An effective way to construct aesthetics culture of tourism is by establishing a cultural aesthetics system of tourism through the construction of aesthetics behavior of tourism, tourism aesthetics system and tourism aesthetics products.

Obasi (Obasi, N. T., 2015) share his thought through his work of 'Tourism Aesthetics and Value' which states that aesthetics has anadjacent relationswith the principles of beauty and artistic taste, in the sense of dealing with critical statements that describe, interpret or evaluate the work of art; the sense of value, significance, form and perception are those things that related to aesthetics. $\mathrm{He}$ mentions that aesthetics of tourism is a branch of aesthetics. The aesthetics of tourism could help people implement aesthetics principles to appreciate natural beauty, artistic beauty and social beauty. It is Obasi's opinion that the aesthetics of tourism is best described through the study of aesthetics activity and aesthetics value through traveling (Obasi, N. T., 2015). From his point of view, aesthetics is an emerging trend of cross-disciplines and relates itself not onlywith geography, but also landscape science, literature, religious culture, folk customs, calligraphy, painting, sculpture, music, dancing, and crafts, and many other, that are the study of aesthetic activities and aesthetic values by way of traveling.

Aesthetics by Kant.Kant's idea on aesthetics can be found in his 'CritiqueofJudgement' that is basicallyKant's third critique whichis a continuation and inseparable part from the origin idea in hisfirst two critiques. Kant's first critique, the 'CritiqueofPureReason' is about apriori condition in an objectiveuniversality of how human mind can have knowledge about the world outside their own selves and how knowledge becomes possible when ones like it. His second critique, the 'CritiqueofPracticalReason' is an attempt to distinguish principles that enable rasional acts and morality. Kant's third critique, the 'CritiqueofJudgement'is about aesthetics and its position associates to the first two critiques, where Kant position 'aestheticsjudgement' between 'logicallynecessary'(for example mathematical theorems) and 'purely subjective' (expression of personal taste).

In his transcendental aesthetics, Kant criticize Baumgarten's interpretation of aesthetics as the philosophy of taste (Bowie, A., 2003). Baumgarten'seffort to brings his judgement onbeautyinto philosophy will be such a waste because it would be rated only to the empirical rule ('sensation') which missed outscientific rule. Kant relates aesthetics more to science rather than sensorical principles. By doing this, Kant clearly separate feeling to reason. Feeling, as seen by Kant is something that is subjective yet universal.

\section{III.METHODOLOGY}

This study is an exploration about "the aesthetics of nature tourism through the philosophical perspective of Immanuel Kant". In doing that, an exploration study was conducted through descriptive researchparticularly literature review methodbyassessing Kant's philosophical reflection on beauty and aesthetics of nature tourism.Data in this study are predominantly Kant's philosophical thoughts, accompanied by other works that relates to, or examines Kant's thought on the aesthetics of nature tourism. The reflection about 'beauty', 'aesthetics' and 'nature tourism' are obtained through journals, books and online sources; while knowledge on nature tourism as well as its beauty and aesthetic,evolve beyond secondary sources that is through observations and empirical experiences. All those primary and secondary data are then embraced to build a thoughtful consideration for the body of this study on the aesthetics of nature tourism through Kant's philosophical perspective. 


\section{IV.RESULT AND DISCUSSION}

\section{A. Result}

Four findings from this study is presented as the following. First of all, pleasure isfound in beauty because 'pleasure' cannot be separated from 'beauty'. According to Kant, aesthetic is a special form of pleasure, and the aesthetics of nature tourism is a pleasure emerged when tourists enjoy nature. Pleasure in the aesthetics of nature tourism is found in beauty of nature.

Secondly, beauty of nature is a subjective appreciation but not merely personal (universal). Aesthetics judgment on beauty of nature is subjective but not personal because feeling as habitation of pleasure in human mind are universal, that everyone might having common sense or sense communis. So aesthetics judgement on beauty of nature is felt the same by others.

Thirdly, Kant distinguishes two types of beauty that is 'free beauty' (pulchritudo vaga) and 'adherent beauty' (pulchritudo adherens). In terms of natural beauty, Kant pronounces that natural beauty comprises of 'perfect beauty' or 'beauty' (associated with balance order') and 'sublime'. The beauty of nature is everything that perceived as 'beauty' and causing 'pleasure' such as sunset, sloping beach, rice fields and so on. 'Sublime' is a natural condition that considered terrifying to people, for example, the vast sea (through the eyes of someone who is in the middle of the sea), storms, cyclones, steep cliffs, and many more.

The fourth result of this studyrelates to morality. The aesthetics of tourism is a symbol of morality through which beauty of nature teaches people to love something unconditionally. The existence of beauty in nature gives us a hint that nature is hospitable to human moralityand that we can only give content to the idea of a purpose for nature that we are led to by our reflection on the purposiveness of organisms by thinking of human moral development as the ultimate end of nature (Kant, I., 2000).

\section{B. Discussion}

Discussion of the four findings of this study is presented as follows.

\section{Pleasure in the Aesthetics of Nature Tourism is found in Beauty of Nature.}

Kant's Pleasure and Aesthetics. Pleasure is a part of human's mind that rested at one's faculty of feeling. As said by Kant, 'faculty of mind' consists of 'faculty of cognition', 'faculty of feeling' and 'faculty of desire'. Faculty of feeling comprises the feeling of 'pleasure' and 'displeasure'. Each of them has their own principles that firstly, a priori to the faculty of cognition; and secondly, the power of judgement for the faculty of feeling of pleasure and displeasure; and reason to the faculty of desire.Kant appreciates aesthetics as a distinctive form of pleasure.According to Kant, "Pleasure is a state of mind in which a representation is in agreement with itself as a ground, either merely for preserving this state itself or for producing its object" (Kant, I., 2000) as the sensible representation of the perfection of an object (Kant, I. , 2000).

Kant's Pleasure in Beauty. The fact that tourism has adjoining connection with pleasure and beauty is in line with Kant's standpoint in his book, the "Critique of Judgement" in which he states about pleasure in beauty (Kant, I. , 2000). Pleasure is considered universal communicable because it is not just built from 'sensation' but 'state of mind' that is cognitive state. Pleasure cannot be separated from beauty or as Kant says, 'pleasure in beauty'. Aesthetics pleasure or pleasure in beauty is about things experienced by others who were with us together at the same time. However it does not necessarily mean that everybody share the same 'pleasure'one can find in 'beautiful' things.

Kant characterize 'pleasure in beauty' as a consciousness of the harmony representation powers, in which people feel their entire 'cognitive faculty' strengthened; a satisfaction that can be communicated to others. It is assumed that everybody should experience the same pleasure over the same beautiful object. 'Pleasure in beauty' is then a free play of imagination and understanding (Kant, I., 2000). The harmony of 'cognitive ability' in free play known as 'cognition in general' is the foundation of 'pleasure in beauty'. Cognition in general is a free play amongst cognitive faculties while harmony is a representation of an object's form of purposiveness [28], subjective condition of cognition or in other word a "stimmung of cognitive power" that is determined only by feeling, not concept (Kant, I. , 2000).

\section{Beauty of Nature is a Subjective Appreciation}


Kant's Beauty. In analyzing 'beauty', not only Kant,I (2000) points out the characteristics of an object of 'beautiful'as an explanation to the meaning of 'judgementoftaste' but also 'synthetical a priorijudgement' as philosophical legitimization ('deduction') of 'judgement of taste' so a 'deduction' shows the legitimacy of a 'class of judgement' which imputes the same satisfaction necessarily to everyone (Crawford, D. W.,2001). For something being titled as 'beauty', commonly through a cognitive assessment of its appearance or performance which is subjective circumstances, reflecting the feelings of a person. According to Kant, different beauty is subjective, not just personal. An aesthetics judgement is thus to be distinguished as one that falls betweenuniversally necessary (or 'logical') and merely personal. An aesthetics judgement is then differentiated by, firstly, the 'judgment of facts' because aesthetics judgment are subjective; secondly, something that is subjective, only because aesthetics judgment requires others to agree;thirdly, a decision based on practical rationality because 'beautiful' has no practical purpose; and lastly, from the things that are just unusual or superficially attractive because 'beauty' has a complete purpose.

The Aesthetics of Nature Tourism. To discuss about beauty is to confer about aesthetics, which is a branch of philosophy that discusses the essence of beauty. Accordingly tourism aesthetics could be categorized as a branch of aesthetics. Kant's philosophical view sees natural beauty as the presentation of the concept of formal (merely subjective) purposiveness and natural endsas the presentation of the concept of a real (objective) purposiveness, one of which we judgethrough taste (aesthetically, by means of the feeling of pleasure), the other through understanding and reason (logically, in accordance with concepts) (Kant, I., 2000). Tourism aesthetics, therefore, lends itself to guide people to appreciate natural beauty, artistic beauty and social beauty by applying principles of aesthetics that assist us to better appreciate natural scenery, understand culture and art, and also understand folk customs from different countries of the world (Obasi, N. T., 2015)

Beauty of nature is a subjective appreciation but not merely personal (universal). So aesthetics judgement on beauty of nature is felt the same by others. Judgment on beauty of nature is not solely based on sensibility or taste alone. Further, beauty of nature is found where nature is seen to produce 'aim without purpose' (zweckmässigkeit ohne zweck) which means that beauty of nature is not merely exists by the object that is nature itself, but related more to mind. The object itself has none of human utility or else useless. For example, beautiful mountain is considered as beauty not because of the usefulness of the mountain but because human mind sees its structure, its harmony with the sky and surroundings, the color of the sky above it, etcetera.

\section{Natural Beauty Consists of Perfect Beauty and Sublime.}

Kant's Beauty \& Sublime.According to Kant, natural beauty comprises of perfect beauty ('beauty') and 'sublime'. The difference between the two extremes of beauty has nothing to do with the nature tourism's object under consideration, but with the attitude of considering the objects. Everything that has beauty of the first kind (perfect beauty) can also be seen to have a second kind of beauty (sublime), if the attention of the view is directed appropriately. The difference between the continuum is based on the level of awareness of sublime element in beauty.The most important and intrinsic difference between beauty and sublime is related to the purpose.

Kant's Sublime. Kant defines 'sublime' as 'absolutely great' moreover 'great beyond all comparison' (Kant, I., 2000). Sublime cannot be regarded as object of senses, for the imagination will not be able to unite the sensual manifold of an absolutely great object into a unity. In other words, there are no sublime objects but only sublime states of subjectivity brought about by encounters with certain classes of objects. Sublime is distinguished into two. The first is 'mathematical sublime' that closely relates to aesthetics, which is so subjective, that it might be relatively small (in relation to the totality provided for particular reason) but also great at the same time. For example the vast sea, the towering mountains, the desert and many more. They can be categorized as sublime because people uses a certain measurement, the self-measurement process that goes on without completion, while it does not have a standard sense of apprehension, so resulting in failure, further causing displeasure. The next is 'dynamic sublime' that is when one is confronted with natural forces beyond his control, such as lightning, volcanoes, hurricanes, infinite ocean, and more. This situation then become sublime when one realizingthe power of a person's physical strength is nothing compared to all those greatness, which make him feel displeasure. But at the same time one can feel those objects are fearful without him being afraid of it because they feel safe from the real danger. At a time the power of 
nature make one realizes his physical weaknesses but at the same time arouses the wakefulness of the unique power of oneself. Then one realizes that nature cannot dominate oneself through the use of reason, that he has the ability to direct its sensory faculty to not fear the dreadful circumstances.

All greatness of storms, oceans, lightning or volcanoes are not real objects of sublime. On the contrary, what is true of sublime is the notion of common sense, namely the idea of 'absolute totality' or 'absolute freedom'. Despite the storm, vast oceans are weaker than the absolute totality; no matter how strong a storm is, it is no different to absolute freedom. Sublime therefore is a kind of 'quick turn' between the fear of immense pleasure and the excitement of seeing the overwhelming devastation. So, it turns out that sublime experiential was deliberately done by all. In the face of sublime, Kant advocated, to "doing violence against imagination" (Kant, I., 2000).

Sublime has a different principle compared to beauty that is aimless. A phenomenon where our understanding confronts something that cannot be controlled; cannot defines the principle of organizing restrictions because it cannot defines any restrictions at all; cannot defines any limits because they are against the power of the imagination that is present. Human understanding fails in confrontation with sublime. Sublime is a disorganization (Kant, I., 2000). This disorganization is not only externally disorganism but also implies human internal systemic disorganization, that arises because of the inability to control it. It threatens the conception of ourselves that is organized and capable of organizing things. In sublime there is something scary. Sublime appears in the form of contrasts for judgment, incompatible with the ability in presentation, and as if to violence against imagination (Kant, I., 2000).

Kant compares sublime and beauty that natural beauty is found by way of looking for reality outside the self, while sublime only on oneself and self-thinking, introducing sublimity into the representation of nature. Beauty brings out, while sublime is turned inward. Briefly it can be said that Kant identified beauty with quality, called aim; sublime by quantity that is unlimited. Beauty is soothing, sublime is annoying. The purpose of beauty is 'understandable by judgment' and thus an object of its own satisfication. The aim of sublime is the opposite, violating the objectives with respect to judgment, not in accordance with our presentative faculty. The two faculties of man, the faculty of reason and sensory, fail to understand sublime.

\section{Tourism Aesthetics as a Symbol of Morality through Beauty of Nature.}

Beauty as a Symbol of Morality. Beauty is the symbol of 'morally good' whereas appreciation of this matter is expected to be done equally by everyone as a duty. The 'morally good' is a nonsensory or rational idea that comes out of the representation of experience. The symbol in this case is defined as sensory experience of something else that is nonsensory. Kant calls it the nonconceptualizable aestheticsidea (inexponible) that constantly comes out of representation or experience through the conceptual meaning. Consequently, rational idea (such as morally good) is considered impossible unreasonable (indemonstrable) because it can never be exemplified by means of people senses. So it is not possible to include aesthetics ideas under a symbolisation of concept or shown experimentally, complementing the weakness of morality concept, its indemonstrability. According to Kant, beauty is shown symbolically in morality (Crawford, D. W., 2001). Then 'beautiful' is a symbol of 'morally good' because our experienceof beauty is an experience of freedom of imagination that is in many ways similar though by no means identical to moral freedom, of which we do not have any direct experience at all. (Kant, I., 2000). The beauty of nature is a symbol of morality through which the beauty of nature teaches people to love something unconditionally.

\section{V.CONCLUSION}

Conclusion of this study are as follows. At first, Pleasure in tourism is found in beauty; or in other word, 'pleasure' cannot be separated from 'beauty'.Pleasure is a part of people's 'faculty of mind'. Pleasure in beauty is a free play of imagination and understanding or cognition in general. The aesthetics of nature tourism is a special form of pleasure that can be found in beauty of nature, that emerge when tourists enjoy nature.

Secondly, beauty of nature is a subjective appreciation but not merely personal (universal); the expression of a preference when we refer to something of which we happen to be especially fond. When we see beautiful things, we are aware of pleasure we derive from them; it is not a function of 
something peculiar to us, some 'personal condition to which our subjective self might party'. But at the same time, aesthetics judgment on beauty of nature eventhough subjective, it is not personal because feeling as habitation of pleasure in human mind are universal, that everyone might having common sense or sense communis.Beauty of nature is found where nature is seen to produce 'aim without purpose' which means that beauty of nature is not merely existed by the object, that is nature itself, but related more to mind.

Thirdly, beauty of nature embraces two forms that is perfect beauty and sublime. The aim of beauty is "understandable by judgment, thus an object of its own satisfication." But sublime is the opposite, namely "violating the objectives with respect to judgment, not in accordance with our presentative faculty." Sublime has a different principle compared to beauty that is aimless. Man's faculty of reason and faculty of sensory, fail to understand sublime. What is true of sublime is the notion of common sense, that is the notion of absolute totality or absolute freedom. In the context of sublime, tourists must fight their imaginations so that they can turn their fear and threats of nature into pleasure.

Last of all, There is a connection between nature tourism witho morality in beauty, especially sublime. Beauty is the symbol of 'morally good' whereas appreciation of this matter is expected to be done equally by everyone as a duty. This 'morally good' is a nonsensory idea, or a rational idea, that comes out of the representation of experience. The beauty of nature is a symbol of morality through which the beauty of nature teaches people to love something unconditionally.

\section{VI.RECOMMENDATION}

Recommendation of this study is that the aesthetics of tourism is a basic substance in the theory and practice of tourism, and there is a need for further study on morality in nature tourism. To sustain the aesthetics of nature tourism, it is compulsory and necessary to embrace morality in beauty especially sublime which implicitly indicates the manifestation of morality in tourism.

\section{REFERENCES}

Barretto, M.(2013). Aesthetics and Tourism, PASOS. Revista de Turismo y Patrimonio Cultural. ISSN 1695-7121Vol. $11 \mathrm{~N}^{\circ} 3$, p.79

Bowie, A.(2003). Aesthetics And Subjectivity: From Kant To Nietzsche, Second Edition, Manchester And New York, Manchester University Press, 2003.

Crawford, D. W.(2001).The Routledge Companion To Aesthetics, New York, Routledge, p. 21-41.

Emerson's lecture https://green.harvard.edu/sites/green.harvard.edu/files/Lecture\%20Tickets.jpeg

Fredman, P. \& Tyrväinen, L.(2011). Frontiers in Nature-based Tourism. Lessons from Finland, Iceland, Norway and Sweden. Oxon: Routledge, p.8.

Hammimaster, Kai.(2002).The German Aesthetic Tradition. Cambridge University Press, p.21.

Kant, I.(2000).Critique of the Power of Judgment. F. T. Lagarde, 1793, edit by Paul Guyer, Cambridge University Press, p.32.

Laarman, J.G., Perdue, R.R.(1988).Tropical Tourism as Economic Activity OTS in Costa Rica, Forestryprivate enterprise initiative workingpaperno 33. Southeastern Center for Forest Economics, Research Triangle Park, North Carolina.

Lucas, P.H.C.(1984).How Protected Areas Can Help Meet Society's Evolving Needs", $72-77$ in J.A. McNeely, and K.R. Miller, eds, "National Parks, Conservation, and Development", Smithsonian Institution Press, Washington D.C.

Mirbach, D.(2009). Magnitudo Aesthetica, Aesthetic Greatness. The Nordic Journal of Aesthetics No. 36-37 (2008/2009), pp. 102-128.

Obasi, N. T.(2015).Tourism Aesthetics and Values", Journal of Tourism and Heritage Studies Vol. 4, No.1\&2. pp.48-56, p. 46.

Peiyin Zhang and Chao Ma.(2011). Research on Value and Approaches of Tourism Aesthetic Construction. 
Rahmanita,Myrza.(2004). Kepariwisataan sebagai Wawasan Pembangunan Nasional Berkelanjutan", Jurnal Ilmiah Pariwisata, Vol. 9 No. 2, Juli 2004, hlm 88-102, ISSN 1411-1527; AKREDITASI No. 52/Dikti/Kep/2002 p.94.

Special Issue.https://doi.org/10.25145/j.pasos.2013.11.040 págs. 79-81

Tatarkiewicz, Wladysla.(1972).The Great Theory of Beauty and Its Decline", The Journal of Aesthetics and Art Criticism, Vol. 31, No. 2. (Winter, 1972), pp. 165-180. P 166.

Tribe, J. Ed.(2009). Philosophical Issues in Tourism. Canada, Channel View Publications.

Valentine, Peter S. (1992). Review: Nature-Based Tourism”.In: Weiler, B.; Hall, C.M., eds.,Special Interest Tourism, London, England:Belhaven: 105-127. 